\title{
INFECTIVE ENDOCARDITIS DUE TO
}

\section{STREPTOCOCCUS AGALACTIAE IN YOUNG AND IMMUNOCOMPETENT WOMAN: A CASE OF STRUCTURALLY NORMAL VALVE ENDOCARDITIS PRESENTED WITH MAJOR STROKE}

\author{
Min Ju SONG, MD, Won Ho KIm, MD, PhD, Sun Hwa LEE, MD, SANG ROK LEE, MD, PHD, \\ KYOUNG-SUK RHEE, MD, PHD, JEI KEON CHAE, MD, PHD AND JAE KI KO, MD, PHD \\ DIVISION OF CARDIOLOGY, DEPARTMENT OF INTERNAL MEDICINE, RESEARCH INSTITUTE OF CLINICAL MEDICINE, CHONBUK NATIONAL \\ UNIVERSITY MEDICAL SCHOOL, JEONJU, KOREA
}

We describe here a 26-year-old woman who presented confusion and right hemiparesis due to embolic obstruction of left internal carotid artery and middle cerebral artery. Transthoracic echocardiography showed structurally normal mitral valve with hypermobile echogenic material suggesting vegetation. The vegetation was disappeared after antimicrobial treatment without surgery.

KEY WORDS: Embolic obstruction · Vegetation · Normal valve.

\section{INTRODUCTION}

Despite advances in medical interventions, infective endocarditis (IE) remains a disease entity with considerable morbidity and mortality. ${ }^{1-4)}$ Poor prognoses of IE are related to valvular regurgitation and abscess formation secondary to tissue destruction, heart failure, and embolic complications." Risk factors of IE in industrialized countries are intravenous drug use, degenerative valve disease, intracardiac devices, health care-associated infection, and hemodialysis. ${ }^{4(6)}$ Most cases of IE seemed to develop in patients with underlying structural heart disease. However, IE rarely involves the valves without predisposing abnormalities.

In Korea, Park et al. ${ }^{7)}$ reported two cases about Streptococcus agalactias (S. agalactiae) IE with diabetes in 2006. In 2009, Lim et al. ${ }^{8)}$ reported about the case of an $S$. agalactiae IE patient who also had advanced gastric cancer. On the contrary, we represent the case of a young, immunocompetent and non-pregnant woman patient who had structurally normal heart. There were major embolic event as the complication of $S$. agalactiae IE. Without any surgery, she made a complete neurological recovery after catheter directed thrombolysis. And The vege- tation was disappeared after antimicrobial treatment without surgery.

\section{CASE}

A 26-year-old woman who was previously healthy and had no history of chronic diseases was presented with sudden onset of mental change. Meticulous history taking revealed her history of dental scaling 6 weeks ago and intermittent fever for last 2 weeks. The patient did not have any obstetric and gynecologic problem such as recent abortion, and urine human chorionic gonadotropin (hCG) test was negative. When she had been transferred to our emergency department she showed confused mental status and fever of $38.5^{\circ} \mathrm{C}$. The blood pressure was $110 / 70 \mathrm{mmHg}$ and the pulse rate was 96 per minute. Grade III/VI systolic murmur was audible at the apical area. Physical examination revealed left eyeball deviation, complete gaze palsy with right hemiparesis (grade III/V), and global aphasia. Electrocardiogram showed sinus tachycardia. It was suspected that she had suffered from cerebroembolic events caused by IE. Emergent cerebral angiography was performed for the evaluation of suspected acute cerebral embo-

- Received: August 25, 2010 •Revised: December 3, 2010 • Accepted: December 7, 2010

- Address for Correspondence: Won Ho Kim, Division of Cardiology, Department of Internal Medicine, Research Institute of Clinical Medicine, Chonbuk National University Medical School, 20 Geonji-ro, Deokjin-gu, Jeonju 561-712, Korea Tel: +82-63-250-1840, Fax: +82-63-250-1680, E-mail: whkim@jbnu.ac.kr

- This is an Open Access article distributed under the terms of the Creative Commons Attribution Non-Commercial License (http://creativecommons.org/licenses/by-nc/3.0) which permits unrestricted non-commercial use, distribution, and reproduction in any medium, provided the original work is properly cited. 
lism. There was embolic obstruction at the distal portion of left internal carotid artery (ICA) (Fig. 1A). Catheter directed infusion by 200,000 unit of the urokinase was performed. Final angiography showed successful recanalization of ICA and middle cerebral artery (MCA) (Fig. 1B). Brain magnetic resonance imaging showed findings of acute infarction in left MCA territory and focal hemorrhage in left lentiform nucleus (Fig. 1C). Transthoracic echocardiography revealed a $0.8 \times 0.5 \mathrm{~cm}$ sized, highly mobile echogenic material on the posterior mitral valve (MV) leaflet suggesting vegetation (Fig. 2A). Three pairs of blood cultures were positive for $S$. agalactiae on admission. On the second day of antibiotic therapy, the bacterial cultures became negative. The patient was administered intravenous ceftriaxone for 4 weeks during the hospitalization. Follow-up echocardiography was performed on the seventh day of antibiotic therapy. It showed disappearance of the vegetation (Fig. 2B). There were no structurally abnormalities on MV (Fig. 2C). Only trivial mitral regurgitation was present after antibiotic therapy. She showed complete neurological recovery and got discharged.

\section{DISCUSSION}

IE features persistent bacteremia resulting from typical organisms for IE and evidence of cardiac valvular involvement (e.g. vegetation, new murmur of valvular regurgitation, paravalvular abscess). ${ }^{6}$ The incidence of IE is approximately 1.76.2 cases per year for every 100,000 patients. Despite advances in medical interventions, IE remains a disease with considerable morbidity and mortality. ${ }^{1-4)}$

In 2007, American Heart Association (AHA) revised the guidelines for IE prophylaxis to more clearly define when IE prophylaxis is recommended. They concluded that prophylaxis is reasonable only for patients with underlying cardiac conditions, for every dental procedures. ${ }^{9)}$ IE has been well known for its occurrence in patients with underlying cardiac problems (e.g. rheumatic valvulopathies, congenital cyanotic heart diseases). However in recent other predisposing factors emerged, such as intravenous drug use, degenerative valve diseases, intracardiac devices, healthcare-associated infection, and hemodialysis. IE is now affecting patients without previously known valve diseases as the result of healthcare-associated procedures.

The mainstay of therapy of IE remains prompt antibiotic therapy. Surgery is indicated in specific patients of IE with congestive heart failure, perivalvular invasive diseases, fungal IE or uncontrolled infection despite maximal antimicrobial therapy. ${ }^{(6) 9)}$

Up to 65 percent of embolic events in IE involve the central nervous system, and neurologic complications develop in 20
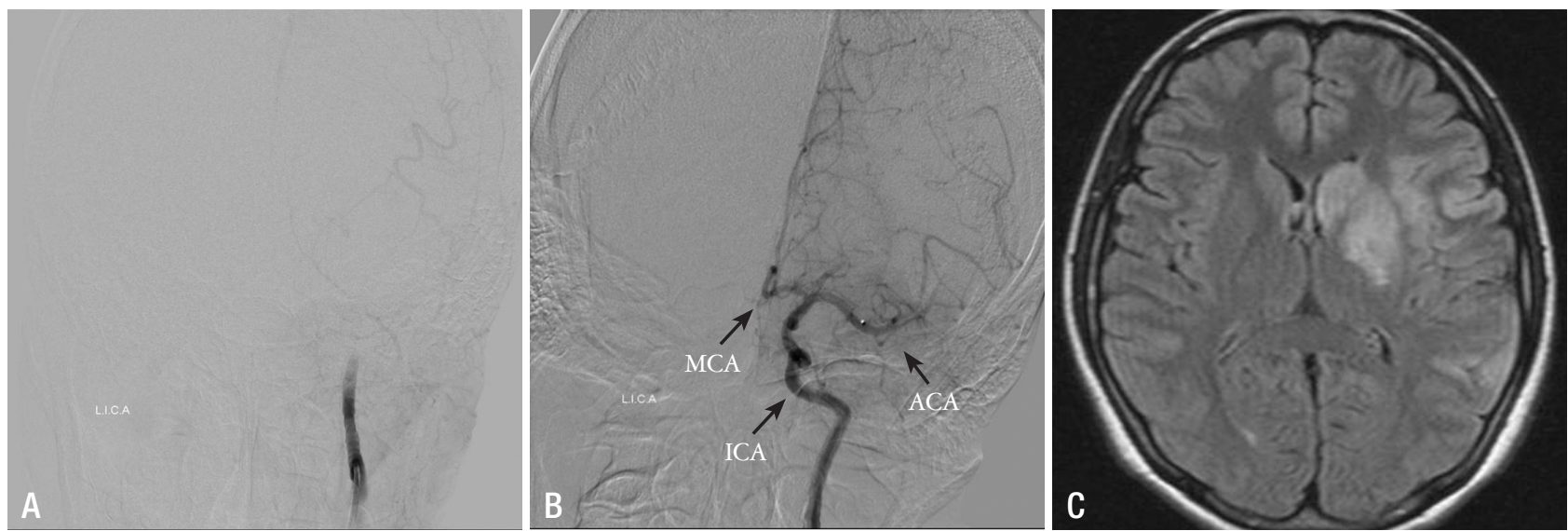

Fig. 1. Cerebral angiography shows complete thrombotic obstruction at the distal portion of left ICA (A). Final angiography after percutaneous thrombolysis shows good patency of left MCA, ACA and ICA (B). Brain MRI shows acute infarction in left MCA territory (circle) and focal hemorrhage in left lentiform nucleus (arrow) (C). ICA: internal carotid artery, MCA: middle cerebral artery, ACA: anterior cerebral artery, MRl: magnetic resonance imaging.
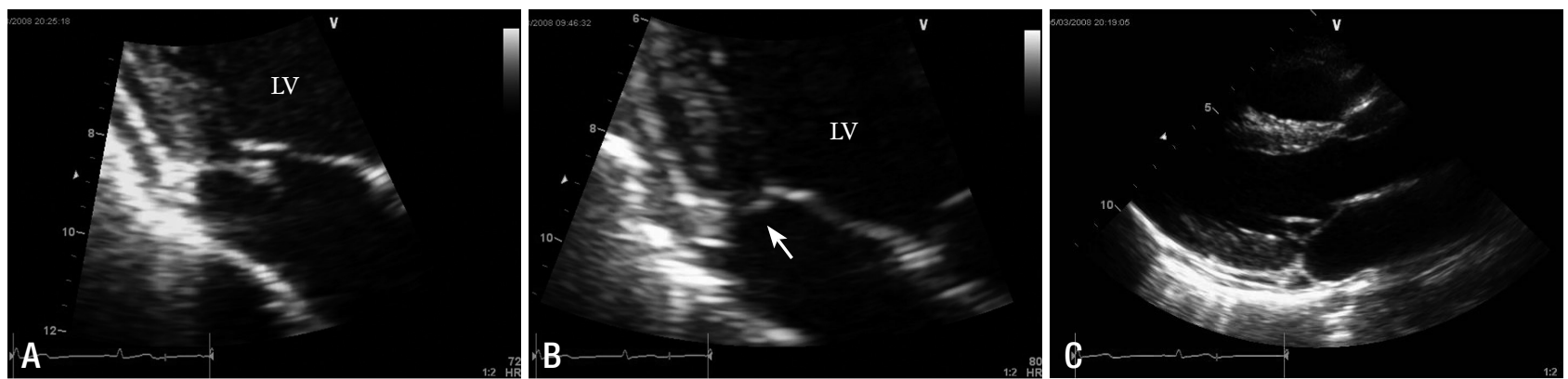

Fig. 2. Transthoracic echocardiography shows $0.8 \times 0.5 \mathrm{~cm}$-sized, echogenic and hypermobile mass on PMVL (A). Follow-up after antimicrobial therapy, echogenic mass was disappeared compared with previous study (B). Transthoracic echocardiography shows structurally normal MV during the end-systolic phase (C). PMVL: posterior mitral valve leaflet, MV: mitral valve. 
to 40 percent of all patients of IE. ${ }^{5-7)}$ The use of thrombolytic therapy in patients with IE suffering from embolic events is controversial. Whether the increased risk of intracranial hemorrhage in patients with IE is to be considered a contraindication for thrombolysis is unclear.

Traditionally $S$. agalactiae was an unusual pathogen in adults who are not pregnant. ${ }^{10)}$ The incidence of invasive $S$. agalactiae infection was recently increasing in both elderly people and those with comorbid conditions. ${ }^{10)}$

In 2010, Ivanova Georgieva et al. ${ }^{11)}$ underwent a cohort study about 27 IE patients due to $S$. agalactiae and reported that $S$. agalactiae IE often develops in patients who have underlying diseases such as diabetes mellitus, liver cirrhosis, malignancy, and abnormalities in immune responses. They suggested that S. agalactiae IE progress aggressively resulting in high mortality. Thus an urgent valve surgery should be performed where necessary such as the disease accompanies complications. ${ }^{1112)}$

In our case, interestingly, the patient was a nonpregnant, immunocompetent and young woman who had no definite cardiac problems. Nevertheless, IE resulted in major stroke a lifethreatening complication.

Decision making regarding the role of medical therapy or surgical intervention is complex and must be individualized to the patient. And it affects improvement of the prognosis in IE patients. In our case, we diagnosed IE with major stroke in early phase with echocardiography. And the patient was complete recovered neurologically by percutaneous intervention and prompt antimicrobial therapy without valve surgery.

\section{REFERENCES}

1. Mylonakis E, Calderwood SB. Infective endocarditis in adults. N Engl J Med 2001;345:1318-30.

2. Paterick TE, Paterick TJ, Nishimura RA, Steckelberg JM. Complexity and subtlety of infective endocarditis. Mayo Clin Proc 2007;82:615-21.

3. Beynon RP, Bahl VK, Prendergast BD. Infective endocarditis. BMJ 2006;333:334-9.

4. Hoen B. Epidemiology and antibiotic treatment of infective endocarditis: an update. Heart 2006;92:1694-700.

5. Vilacosta I, Graupner C, San Roman JA, Sarria C, Ronderos R, Fer- nandez C, Mancini L, Sanz O, Sanmartin JV, Stoermann W. Risk of embolization after institution of antibiotic therapy for infective endocarditis. $J$ Am Coll Cardiol 2002;39:1489-95.

6. Baddour LM, Wilson WR, Bayer AS, Fowler VG Jr, Bolger AF, Levison ME, Ferrieri P, Gerber MA, Tani LY, Gewitz MH, Tong DC, Steckelberg JM, Baltimore RS, Shulman ST, Burns JC, Falace DA, Newburger JW, Pallasch TJ, Takahashi M and Taubert KA. Infective endocarditis: diagnosis, antimicrobial therapy, and management of complications: a statement for healthcare professionals from the Committee on Rheumatic Fever, Endocarditis, and Kawasaki Disease, Council on Cardiovascular Disease in the Young, and the Councils on Clinical Cardiology, Stroke, and Cardiovascular Surgery and Anesthesia, American Heart Association: endorsed by the Infectious Diseases Society of America. Circulation 2005; 111:e394-434.

7. Park J, Choi SN, Kim HO, Jeong YG, Hwang JY, Kim JW, Bae IG. Two cases of infective endocarditis with multiple brain infarcts caused by Streptococcus agalactiae. Infect Chemother 2006;38:271-6.

8. Lim TK, Kim SJ, Kim JH, Cho CB, Kim YJ, Kim KI, Lee SS. A case of infective endocarditis caused by Streptococcus agalactiae, in a patient with advanced gastric cancer. Korean J Med 2009;77:S209-12.

9. Wilson W, Taubert KA, Gewitz M, Lockhart PB, Baddour LM, Levison $\mathrm{M}$, Bolger A, Cabell CH, Takahashi M, Baltimore RS, Newburger JW, Strom BL, Tani LY, Gerber M, Bonow RO, Pallasch T, Shulman ST, Rowley AH, Burns JC, Ferrieri P, Gardner T, Goff D, Durack DT. Prevention of infective endocarditis: guidelines from the American Heart Association: a guideline from the American Heart Association Rheumatic Fever, Endocarditis, and Kawasaki Disease Committee, Council on Cardiovascular Disease in the Young, and the Council on Clinical Cardiology, Council on Cardiovascular Surgery and Anesthesia, and the Quality of Care and Outcomes Research Interdisciplinary Working Group. Circulation 2007;116:1736-54.

10. Farley MM, Harvey RC, Stull T, Smith JD, Schuchat A, WegnerJD, Stephens DS. A population-based assessment of invasive disease due to group B streptococcus in nonpregnent adults. N Engl J Med 1993;328: 1807-11.

11. Ivanova Georgieva R, Carcia Lopez MV, Ruiz-morales J, MartinezMarcos FJ, Lomas JM, Plata A, Noureddine M ,Hidalgo-Tenorio C, Reguera JM, De la Torre Lima J, Galvez Aceval J, Marquez M, de Alarcon A. Streptococcus agalactiae left-sided infective endocarditis. Analysis of 27 cases from a multicentric cohort. J Infect 2010;61:54-9.

12. Sambola A, Miro JM, Tomas MP, Almirante B, Moreno-Torrico A, Gurgui M, Martinez E, Del Rio A, Azqueta M, Marco F, Gatell JM. Streptococcus agalactiae infective endocarditis: analysis of 30 cases and review of the literature 1962-1998. Clin Infect Dis 2002;34:1576-84. 